Documentation et bibliothèques

\title{
Le discours sur la lecture et les bibliothèques au Québec depuis
} 1970

\section{Reading and Public Libraries in Québec Since 1970 \\ Discurso sobre la lectura y las bibliotecas en Québec a partir de 1970}

\section{Marcel Lajeunesse}

Volume 56, numéro 3, juillet-septembre 2010

URI : https://id.erudit.org/iderudit/1029120ar

DOI : https://doi.org/10.7202/1029120ar

Aller au sommaire du numéro

Éditeur(s)

Association pour l'avancement des sciences et des techniques de la documentation (ASTED)

ISSN

0315-2340 (imprimé)

2291-8949 (numérique)

Découvrir la revue

Citer cet article

Lajeunesse, M. (2010). Le discours sur la lecture et les bibliothèques au Québec depuis 1970. Documentation et bibliothèques, 56(3), 97-104.

https://doi.org/10.7202/1029120ar

\section{Résumé de l'article}

Il y a 50 ans, en décembre 1959, le Québec se donnait une loi des bibliothèques publiques. Une politique de lecture publique pouvait alors être mise en place. Le discours québécois sur la lecture et sur les bibliothèques depuis les années 1970 a pris en compte cette nouvelle donne, et, de ce fait, il tranche avec celui qui était véhiculé antérieurement. On peut y noter des moments forts. Ils se rattachent au plan Vaugeois, à la Politique du livre et de la lecture et à la création de la Grande Bibliothèque.
Tous droits réservés $@$ Association pour l'avancement des sciences et des techniques de la documentation (ASTED), 2010
Ce document est protégé par la loi sur le droit d'auteur. L'utilisation des services d'Érudit (y compris la reproduction) est assujettie à sa politique d'utilisation que vous pouvez consulter en ligne.

https://apropos.erudit.org/fr/usagers/politique-dutilisation/ 


\title{
Le discours sur la lecture et les bibliothèques au Québec depuis 1970
}

\author{
MARCEL LAJEUNESSE
}

EBSI, Université de Montréal

marcel.lajeunesse@umontreal.ca

\begin{abstract}
RÉSUMÉ | ABSTRACTS | RESUMEN
Il y a 50 ans, en décembre 1959, le Québec se donnait une loi des bibliothèques publiques. Une politique de lecture publique pouvait alors être mise en place. Le discours québécois sur la lecture et sur les bibliothèques depuis les années 1970 a pris en compte cette nouvelle donne, et, de ce fait, il tranche avec celui qui était véhiculé antérieurement. On peut y noter des moments forts. Ils se rattachent au plan Vaugeois, à la Politique du livre et de la lecture et à la création de la Grande Bibliothèque.
\end{abstract}

\section{Reading and Public Libraries in Québec Since 1970}

Fifty years ago, in December 1959, Québec adopted a public libraries act. This legislation helped promote a public reading policy and has influenced the development of reading and public libraries in Québec since the 1970s. As a result, a departure from the position promoted earlier became possible. Intense periods, such as the Vaugeois plan, the book and reading policy and the creation of the Grande Bibliothèque, can be observed.

Discurso sobre la lectura y las bibliotecas en Québec a partir de 1970

Hace 50 años, en diciembre de 1959, se estableció una ley de bibliotecas públicas en Québec y se pudo implementar una política sobre la lectura pública. El discurso quebequense sobre la lectura y sobre las bibliotecas a partir de 1970 toma en cuenta esta nueva situación y, por lo tanto, contrasta con el discurso esbozado anteriormente. Podemos observar momentos importantes que se vinculan con el plan Vaugeois, con la política del libro y de la lectura, y con la creación de la Grande Bibliothèque (Gran biblioteca).
A U XIXe siècle, l'alphabétisation et la lecture sont devenues des priorités pour les sociétés occidentales. Le même phénomène s'est produit au Québec avec les politiques d'éducation des surintendants Jean-Baptiste Meilleur (1842-1855) et PierreJoseph-Olivier Chauveau (1855-1867). La généralisation de la lecture a fait en sorte que celle-ci est devenue " objet de discours, de prises de parole multiples édictant des normes ou constatant des faits, qu'elle est prétexte à débats dans l'espace public et même enjeu dans les sphères du pouvoir " (Chartier et Hébrard, 1989: 9). Mais y eut-il jamais un temps où lire allait de soi, où la lecture n'ait suscité commentaires, inquiétudes ou polémiques? La question de l'écrit et de ses usages a fait l'objet de plusieurs discours: discours de l'Église, discours de l'école et aussi discours des bibliothécaires.

La lecture au Québec a fait l'objet d'un grand nombre d'études et d'observations pour le XIX $\mathrm{X}^{\mathrm{e}}$ siècle et la première moitié du XX $\mathrm{XX}^{\mathrm{e}}$ siècle. Réjean Savard y a consacré quelques articles (Savard et Delisle, 1996; Savard, 1997 ; Delisle et Savard, 1998), Yvan Lamonde et Louis-Georges Harvey ont analysé l'Institut canadien de Montréal (Harvey et Olsen, 1986 ; Lamonde, 1991) et nous avons étudié l'CEuvre des bons livres et le Cabinet de lecture paroissial (Lajeunesse, 1982). En 1995, la revue Documentation et bibliothèques a livré en quatre articles une synthèse commode de l'évolution de la lecture publique, de la Conquête à 1960. La publication récente des trois volumes de l'Histoire du livre et de l'imprimé au Canada représente une avancée considérable de la connaissance de l'offre et de la réception du livre en notre milieu (Lamonde et Fleming, 2004-2007).

Tous ces articles montrent essentiellement que, pendant plus d'un siècle, des années 1840 à 1960, on observe la permanence du discours sur les bonnes/ mauvaises lectures et sur la dichotomie bibliothèques paroissiales/bibliothèques publiques. On y décrit aussi le discours à propos des bibliothèques enfantines ainsi que la vision de l'enfant vis-à-vis du livre et de la bibliothèque, ou plutôt la position de la bibliothèque face à l'enfant (Savard et Delisle, 1996). De son côté, le bibliothécaire fut souvent relégué à un rôle de gardien de la morale sous la tutelle religieuse. L'examen du programme de l'École de bibliothécaires des années 1940 et 1950 montrait bien que celui-ci visait d'abord à préserver la spécificité religieuse et linguistique du Canada français (Delisle et Savard, 1998). Pierre Hébert 


\section{Les années 1970 sont marquées par de nombreuses actions concernant les bibliothèques publiques, le livre et la lecture.}

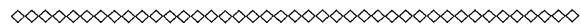

a démontré, dans ses deux livres sur la censure, toute l'importance de celle-ci dans la diffusion de l'imprimé (Hébert, 1997 ; 2004). L'analyse du Bulletin de l'ACBLF, publié de 1955 à 1972, met en évidence le basculement des valeurs de la société québécoise au moment de la Révolution tranquille avec la fin de l'Index et d'une certaine censure et le passage d'une vision morale de la lecture publique à une conception professionnelle et scientifique de celle-ci (Harvey et Olsen, 1986; Lafortune et Viens, 1998). Le bibliothécaire cesse alors de se considérer comme le gardien moral des lectures de la société, comme le médecin des âmes. Il devient un professionnel des bibliothèques et de l'information (Lajeunesse, 2005).

Le présent texte discourt sur la lecture développée au cours des quatre dernières décennies. Au cours de cette période, qui n'avait pas jusqu'à présent fait l'objet d'une étude, on observe un discours qui diffère de celui qui a été véhiculé au cours des périodes précédentes. La présence d'une action gouvernementale et de fortes infrastructures en lecture publique fait la différence.

\section{Développement des bibliothèques publiques et politique du livre}

À la suite du vote de la loi des bibliothèques publiques en décembre 1959 et à la création du Service des bibliothèques publiques l'année suivante, la décennie 1960 est consacrée à la mise en place d'une politique de lecture publique. Laction gouvernementale s'exerce surtout auprès des bibliothèques municipales naissantes par le biais de subventions et par la création des deux premières bibliothèques centrales de prêt $(B C P)$, en Mauricie et en Outaouais, desservant les municipalités de moins de 5000 habitants.

Les années 1970 sont marquées par de nombreuses actions concernant les bibliothèques publiques, le livre et la lecture. Mentionnons notamment la réglementation du marché du livre en 1971 (politique du livre) dont l'objet principal fut le développement et la stabilisation des librairies par l'obligation pour les bibliothèques subventionnées, publiques, collégiales et scolaires, d'acheter leurs livres dans des librairies agréées par le ministère des Affaires culturelles. Cette décennie s'est ouverte par la création de la Bibliothèque centrale de prêt du Saguenay-Lac-Saint-Jean, suivie, au cours de ces 10 ans, par la création de six autres BCP.
Les années 1970 donnent aussi lieu aux premières études scientifiques sur les habitudes de lecture de groupes particuliers de lecteurs. Le sociologue Gilbert Gagnon, du Service des bibliothèques publiques du ministère des Affaires culturelles, mène une enquête auprès des lecteurs de la région de la Mauricie (Gagnon, 1970). Il observe que la lecture des revues est très pratiquée dans cette région et que la lecture de ces imprimés ne conduit pas nécessairement à la lecture des livres. Janina-Klara Szpakowska, professeure à l'École de bibliothéconomie de l'Université de Montréal, publie la première de plusieurs études sur le comportement culturel des adolescents montréalais (Szpakowska, 1970). Elle analyse les profils culturels des jeunes montréalais de 15 à 17 ans et conclut que $40 \%$ des jeunes trouvent un intérêt, une "disponibilité intellectuelle et temporelle " pour la lecture, mais que la lecture ne vient qu'au cinquième rang de leurs loisirs après l'écoute de disques, la télévision, les discussions avec les amis et la pratique des sports. La variable sexe n'apparait pas à la chercheure comme un facteur décisif en ce qui concerne le choix de la lecture.

En 1979, une étude interne du ministère des Affaires culturelles montre que, malgré une augmentation du pourcentage de la population québécoise desservie, de $59,7 \%$ en 1973 à $76,8 \%$ en 1979 , les indicateurs relatifs à la lecture publique stagnent. Entre ces deux années, le pourcentage d'usagers inscrits est passé de $24,2 \%$ à $22,9 \%$, et le nombre de prêts par habitant est demeuré le même à 2,9 , malgré une augmentation appréciable des dépenses par habitant, de 2,24 \$ à 7,52 \$. La faiblesse des infrastructures est révélée par la carence du personnel : $20 \%$ des bibliothèques n'ont alors aucun employé à plein temps et $60 \%$ n'ont aucun bibliothécaire professionnel pour les diriger et les animer. En 1979, 131 bibliothécaires, dont 52 pour la seule ville de Montréal, œuvrent dans les bibliothèques publiques, soit un rapport d'un bibliothécaire pour 35000 habitants, alors que la norme établie par le Service des bibliothèques publiques au milieu de la décennie 1970 est de 1 pour 6000 habitants. Il y a quelques exceptions à ce tableau pessimiste. Elles se retrouvent dans des villes à majorité anglo-saxonne, telles Westmount avec cinq bibliothécaires pour 22500 habitants, Mont-Royal avec quatre bibliothécaires pour 20500 habitants et PointeClaire avec cinq bibliothécaires pour 25900 habitants (Lacroix, 1979). En 1977, une autre étude comparant le Québec et l'Ontario avait d'ailleurs montré qu'en Ontario les bibliothèques publiques possèdent 2,43 livres par habitant, emploient un bibliothécaire par 8183 habitants, occupent un espace de 41,1 mètres carrés par 1000 habitants et dépensent $12,98 \$$ par Ontarien; au même moment, les bibliothèques publiques du Québec possèdent 0,89 livre par habitant, emploient un bibliothécaire par 44322 habitants, occupent un espace de 10,6 mètres carrés par 1000 habitants et dépensent 3,80 \$ par Québécois (Gagnon, 1987). 


\section{Le plan Vaugeois et ses lendemains}

Denis Vaugeois, nouveau ministre des Affaires culturelles en 1978 , est convaincu qu'un coup de barre s'impose pour stimuler la lecture au Québec. Le plan quinquennal (1980-1985) qui porte son nom découle de ce constat important. Le plan Vaugeois prend son origine dans les nombreuses études et interrogations de la seconde moitié de la décennie 1970 concernant la politique de la culture et de la lecture au Québec. Mentionnons notamment: le document signé en 1976 par le ministre des Affaires culturelles de l'époque, Jean-Paul L'Allier, Pour l'évolution de la politique culturelle; le Mémoire sur une politique du livre et de la lecture au Québec du Comité consultatif du livre en 1977 ; le document du sous-ministre des Affaires culturelles Claude Trudel, Pour une véritable politique de la lecture au Québec, en 1977; et la Politique québécoise de développement culturel, en 1978. Ces divers rapports ont servi à documenter une action gouvernementale en lecture publique.

Dans le plan Vaugeois, on retrouve des mesures généreuses concernant la construction et le réaménagement des locaux de bibliothèques, une allocation pour l'embauche de bibliothécaires professionnels et une aide supplémentaire pour l'achat de livres pour compenser les coûts additionnels des livres dus à la nouvelle loi 51 (Loi sur le développement des entreprises québécoises dans le domaine du livre, L.R.Q. chap. D-8.1) qui réglemente le domaine du livre au Québec. Le résultat de ces diverses mesures a l'effet d'un coup de fouet sur la lecture publique. En cinq ans, la population desservie par les bibliothèques publiques passe de $77 \%$ à $86 \%$, le nombre de prêts par habitant de 2,9 à 4,3 et les dépenses affectées à la lecture publique de 7,52 \$à 13,77\$. Cependant en dépit de ces résultats encourageants, la situation québécoise ne rattrape pas, tant s'en faut, la moyenne canadienne dans ce domaine.

En 1984, le ministère des Affaires culturelles fait le point dans un document intitulé La lecture au Québec, document d'orientation (La lecture au Québec, 1984). Les éléments principaux de ce document ministériel ont trait au goût et au plaisir de lire, au développement des habitudes de lecture chez les jeunes Québécois, à l'accessibilité du livre dans l'environnement quotidien et à la nécessaire animation du livre en divers milieux. Des études du ministère des Affaires culturelles, publiées en 1984, montrent aussi "que le livre ne fait pas partie de l'environnement quotidien des Québécois, [que] la lecture n'est pas intégrée aux activités de bien des gens et [que] plusieurs personnes ont une perception négative $d u$ livre et de la lecture » (Garon, $1984: 111)$.

Un nouveau gouvernement dirigé par le Parti libéral (1985), qui veut passer d'un "État maître d'œuvre et d'un État providence à un État catalyseur ", effectue des coupures importantes dans le domaine de la culture en général, et dans celui des bibliothèques publiques en particulier. À la suite des fortes réactions du milieu, le gouvernement crée la Commission d'étude sur les bibliothèques publiques, présidée par Philippe Sauvageau (Commission d'étude, 1987). Le rapport de la Commission a l'avantage de dresser un tableau complet de l'évolution de la lecture publique depuis ses débuts, dans les années 1960, et d'esquisser les mesures nécessaires à une nouvelle étape de son développement. Parmi les conclusions du rapport, on note la nécessité d'une nouvelle loi des bibliothèques publiques, celle de 1959 étant devenue obsolète, la création d'un nouveau Service des bibliothèques publiques, pour remplacer celui qui a été aboli en 1982 à la suite d'une réorganisation administrative, le financement de travaux urgents d'informatisation des bibliothèques, et une augmentation substantielle de la participation financière de l'État. La participation des bibliothécaires et de leurs associations est enthousiaste lors des séances de la Commission d'étude à travers le Québec et les attentes sont très élevées.

Le domaine de la culture est sans cesse scruté et analysé au Québec. Une fois de plus, en 1991, le gouvernement du Québec commande une étude de l'ensemble de la scène culturelle québécoise. Il créé la Commission de la culture, que préside le haut fonctionnaire Roland Arpin. La création du ministère de la Culture est issue, en 1992, des travaux de cette Commission. Dans le Rapport Arpin, en vue d'une politique de la culture au Québec, le livre, la bibliothèque et la lecture sont peu présents, alors qu'ils auraient dû être au cœur même du projet de politique. On retrouve pourtant présenté clairement, dans les divers mémoires des associations et des regroupements de bibliothécaires, des bibliothèques et des écoles de bibliothéconomie qui ont été soumis à la Commission, le discours des bibliothécaires sur la lecture au début de la décennie 1990 (Brault, 1992). Plusieurs idées y sont développées :

- la langue, la lecture et la culture sont en corrélation vitale et elles sont des facteurs de progrès;

- la lecture est l'activité la plus fondamentale dans le processus de formation et de développement intellectuel et culturel des citoyens ;

- le droit de lire est considéré comme l'activité culturelle de base ;

- la bibliothèque est un service complet de lecture publique et d'information.

Une politique de la lecture passe par le développement des bibliothèques publiques, développement fortement lié à une législation sur celles-ci, un financement adéquat et un support de l'État. Il est également prioritaire de se doter de bibliothèques scolaires dynamiques et d'inciter les jeunes à la lecture. Enfin, il est impératif de renforcer les institutions nationales comme la Bibliothèque nationale du Québec et les Archives nationales du Québec. 


\section{Chez les jeunes, la lecture n'a pas diminué; elle a été détournée en partie de ses supports traditionnels vers d'autres supports qui font appel aux nouvelles technologies de l'information.}

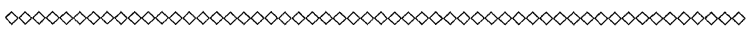

À la même période, soit au début des années 1990, le milieu des bibliothèques est irrité par le peu de mesures issues des deux rapports importants des dernières années, le Rapport Sauvageau déjà mentionné et le Rapport Bouchard sur les bibliothèques scolaires (Comité d'étude sur les bibliothèques scolaires, 1989). Cette étude sur les bibliothèques scolaires avait en effet suscité beaucoup d'espoir. On espérait voir émerger un réseau de bibliothèques dans les écoles. On souhaitait voir confié à la bibliothèque scolaire un rôle particulier pour soutenir l'acquisition de la compétence linguistique au regard de la lecture et de l'expression écrite. $\mathrm{Vu}$ l'extrême faiblesse des infrastructures des bibliothèques scolaires québécoises, la tâche s'annonçait immense. Le Rapport Bouchard est resté lettre morte. Les deux rapports étaient liés par leur objectif commun, celui de donner le goût de la lecture et d'apprivoiser les jeunes à la lecture.

À l'époque, les professionnels affectés à la lecture publique font le constat qu'une portion importante de la population a de la difficulté à fréquenter les bibliothèques publiques et à utiliser les collections. On évalue à $25 \%$ le pourcentage des lecteurs faibles. François Séguin (1992) soutient qu'il faut offrir à ces lecteurs une collection Hi-Lo (High Interest-Low Level Books) comme l'ont fait les bibliothèques publiques américaines; l'approche peut permettre de faire cheminer un lecteur vers des lectures plus complexes. Mais une telle collection a besoin d'être développée, animée et une aide personnalisée du bibliothécaire s'impose. L'implantation d'une telle approche exige une volonté professionnelle, une détermination politique et, bien sûr, des ressources matérielles et humaines.

Pour Bruno Roy, alors président de l'Union des écrivains québécois (UNEQ), le rôle de la bibliothèque est "d'être un lieu de lecture et de recherche, une institution documentaire, une centrale de prêts, un centre de conservation du patrimoine littéraire et un lieu d'accessibilité intellectuelle» (Roy, 1994 : 95). Selon lui, lorsqu'il s'agit de positionner la bibliothèque publique par rapport à l'épanouissement culturel des individus et de leur société, il faut éviter de confondre accès à la culture et loisir culturel. Les bibliothèques sont d'importants lieux de fréquentation des livres et les premiers lieux de conservation du patrimoine littéraire. En dernière analyse, le livre sera toujours représentatif d'un état actuel de civilisation.
Depuis la décennie 1990, le taux des abonnés à la bibliothèque publique au Québec continue de stagner autour de $30 \%$. On avait pourtant espéré une hausse du nombre et du pourcentage d'abonnés. En 1994, Denis Boisvert rapporte qu'une étude prospective, réalisée l'année précédente par la Direction de la recherche, de l'évaluation et des statistiques du ministère de la Culture et des Communications, prévoyait un taux de fréquentation de $46 \%$ en 2011 ; cette hausse est loin de s'être matérialisée. On a même constaté une baisse des lecteurs entre 1979 et 1999, et cela tant chez les femmes que chez les hommes (Garon, 2004). Dans son analyse de vingt années de lecture au Québec, Garon rappelle qu'un peu plus de la moitié de la population lit régulièrement des livres, que la proportion de ceux qui lisent moins de 10 livres par an a augmenté entre 1979 et 1999, tandis que la proportion de ceux qui lisent 50 livres et plus par an a diminué. La pratique de la lecture est à son plus haut niveau dans les régions de Montréal et de Québec et elle diminue à mesure que l'on s'en éloigne. La lecture demeure une activité plutôt féminine. Les différences entre les générations ont presque disparu. Il y a une baisse de lecture chez les personnes scolarisées, alors que celles qui le sont moins lisent plus qu'avant. Chez les jeunes, la lecture n'a pas diminué; elle a été détournée en partie de ses supports traditionnels vers d'autres supports qui font appel aux nouvelles technologies de l'information.

\section{La Politique du livre et de la lecture}

L'année 1998 fut une année faste pour la promotion de la lecture au Québec. En avril, le premier ministre Lucien Bouchard convoque dans la Capitale nationale un Sommet sur le livre et la lecture. Cette rencontre a été précédée et préparée par deux documents du ministère de la Culture et des Communications. Le premier de ces documents, intitulé Le temps de lire, un art de vivre. État de la situation de la lecture et du livre au Québec (121 p.) est un état des lieux; on y fait état des habitudes de lecture des Québécois, des compétences en lecture et en apprentissage de la lecture, de la mission des bibliothèques scolaires comme lieux d'apprentissage à la lecture et comme lieux d'accès à l'écrit, des bibliothèques publiques et des librairies et enfin de l'édition de livres et des médias écrits au Québec. On y apprend que $43 \%$ des Québécois ne lisent jamais ou rarement des livres, que l'état des bibliothèques scolaires est préoccupant, que les bibliothèques publiques ont connu une croissance remarquable depuis les années 1960, mais qu'il subsiste des disparités considérables entre les régions en ce qui concerne les pourcentages d'abonnés, avec par exemple 39,2\% dans le Bas-Saint-Laurent et $19,4 \%$ en Abitibi-Témiscamingue.

Le second document, Le temps de lire, un art de vivre. Projet de politique de la lecture et du livre 
(94 p.), formule plusieurs objectifs devant se traduire en mesures d'action gouvernementale :

- susciter chez les jeunes, dès la petite enfance, l'éveil à la lecture et le goût de lire ;

- faire de l'école un milieu privilégié pour l'accès à la lecture ;

- améliorer la qualité des services de bibliothèques publiques et de la coopération entre l'ensemble des bibliothèques ;

- donner aux Québécois une institution d'envergure nationale (Grande Bibliothèque) ;

- offrir aux citoyens une large gamme d'écrits et de livres;

- susciter des activités d'animation et de sensibilisation à la lecture et à l'écrit.

En somme, il s'agit de faire de la lecture, l'une des grandes voies du savoir et de l'imaginaire, un axe majeur du développement culturel de la société québécoise.

Diverses actions et mesures émergent des études préparatoires et des conclusions du Sommet lui-même. En premier lieu, la Grande Bibliothèque est créée par un vote unanime de l'Assemblée nationale en 1998. Sa création a fait l'objet des travaux d'un comité présidé par l'ancien ministre Clément Richard, qui avait pour mandat d'étudier la faisabilité d'implanter une bibliothèque de grande taille à Montréal. Cette bibliothèque a ouvert ses portes en 2005 avec le succès que l'on connaît.

Un peu plus tard, en 2001, l'Observatoire de la culture et des communications du Québec voit le jour. Son rôle est de suivre le développement du livre, des bibliothèques, de la librairie et des divers médias et de mener des travaux de recherche dans ces domaines. Dans les années qui suivent, deux ouvrages contribuent à faire le point sur le phénomène du livre et de la lecture. Le livre Les chiffres des mots. Portrait économique du livre au Québec de Marc Ménard, publié en 2001, brosse un tableau intéressant et utile de l'industrie du livre au Québec. En 2004, l'Observatoire publie un État des lieux du livre et des bibliothèques qui s'avère un livre de référence sur l'édition, la librairie et plusieurs types de bibliothèques (nationale, publiques, universitaires et de collège).

Les bibliothèques scolaires sont depuis longtemps le secteur des bibliothèques le plus négligé au Québec. Combien de rapports et d'études ont fait état, au fil des années, de leurs collections périmées, de l'absence de personnel spécialisé, du détournement des faibles budgets vers d'autres affectations dans les écoles? Le Sommet a conclu à la nécessité d'un réinvestissement majeur du gouvernement dans ces bibliothèques. Depuis quelques années, le ministère de l'Éducation, du Loisir et des Sports porte attention à la mise en place de véritables bibliothèques scolaires. Il reste à espérer que les espoirs ne seront pas déçus cette fois.

\section{Il s'agit de faire de la lecture, l'une des grandes voies du savoir et de l'imaginaire, un axe majeur du développement culturel de la société québécoise.}

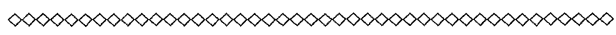

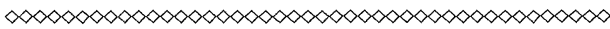

De leur côté, les bibliothèques publiques sont au premier rang d'une politique de la lecture et leur contribution est essentielle à la réalisation de cet objectif. Il a été décidé au Sommet qu'il s'imposait d'enrichir les collections pour atteindre cinq ans plus tard, en 2003, une moyenne de trois livres par habitant, ce qui impliquait l'acquisition chaque année d'un million de volumes pour le quinquennat 1998-2003. Dans les faits, la proportion de livres par habitant est passée de 2,45 en 1999 à 2,83 en 2005, et l'ouverture de la Grande Bibliothèque a sans doute contribué grandement à ce dernier résultat. Quant à l'objectif revu d'un bibliothécaire par 10 ooo habitants au lieu de 6000 , il est loin d'être atteint avec la présence en bibliothèques publiques de 390 bibliothécaires seulement en 2005 (Leroux et Lajeunesse, 2007).

En 1997, un collectif dirigé par Gilbert Gagnon portait un regard d'ensemble sur la culture dans la société québécoise (Gagnon, 1997). On y observait que la lecture venait au deuxième rang des activités préférées après le sport et les activités physiques. Ce tableau était modulé en prenant en compte plusieurs variables. Le choix de la lecture est le choix d'une femme sur deux et d'un homme sur quatre. La pratique de la lecture augmente chez les plus de 45 ans et diminue chez les jeunes. La situation socioprofessionnelle et le fait d'habiter une grande ville sont des facteurs qui favorisent la lecture. Dans le choix des lectures, ce sont par ordre décroissant les quotidiens, les revues, les livres qui sont privilégiés.

La Bibliothèque Gabrielle-Roy de Québec tenait en 2002 un séminaire sur la lecture comme mode d'accès privilégié à la connaissance et sur le rôle des bibliothèques publiques (Goyette, 2002). La question de la place que l'on doit accorder à la promotion de la lecture dans la politique culturelle est au centre des discussions. Les participants affirment que la lecture rend possible l'éveil à soi-même et à autrui, qu'elle donne un sens au monde et que le développement de l'intelligence est lié à l'acte de lire. Pour que la lecture et l'accès à la connaissance donnent leurs fruits, il faut qu'ils accroissent la capacité critique, la diversité démocratique, le rattachement à des valeurs partagées. Lire est un plaisir, mais c'est aussi l'apprentissage de la citoyenneté et l'approfondissement de la condition humaine. Par ailleurs, on constate aussi que la lecture est dans une situation précaire en tant que pratique culturelle. La fréquentation des bibliothèques publiques a augmenté, 


\section{Il s'agit de réintégrer la culture et la lecture au premier rang et de l'affirmer haut et fort dans le discours des bibliothèques.}

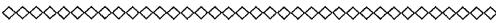

mais les études démontrent que le nombre de lecteurs stagne ou a même diminué. Au Québec, le paradigme de la bibliothèque-loisir «a la vie dure. On a beaucoup investi dans les bibliothèques publiques depuis les années 1960 , on a crée beaucoup de bibliothèques, mais on ne peut prétendre qu'elles furent portées par un projet de société » (Payeur, cité dans Goyette, 2002 : 92-93).

De son côté, dès la conception de la Grande Bibliothèque en 1998, la présidente-directrice générale Lise Bissonnette a mis l'accent sur la bibliothèque publique en tant qu'institution culturelle. Cette vision de la bibliothèque publique, Lise Bissonnette l'aura affirmée avec force durant toutes les années de son directorat. Pour elle, "les pistes les plus prometteuses de développement et de croissance du rôle des bibliothèques dans la cité sont d'ordre culturel. Ce n'est pas en nous substituant aux hotels de ville, aux agences d'information, aux médias, aux chambres de commerce, aux groupes communautaires que nous apporterons notre pierre aux mutations actuelles de nos sociétés, mais en tablant sur notre spécificité culturelle, qui est réelle. Dépositaires du patrimoine publié, nous sommes les seules institutions à pouvoir le transmettre, et le faire vraiment connaitre et rayonner" (Bissonnette, 2004b : 210).

Cette affirmation du concept de bibliothèque publique culturelle sera souvent reprise au tournant des années 2000. Il s'agit de réintégrer la culture et la lecture au premier rang et de l'affirmer haut et fort dans le discours des bibliothèques. Elle est en quelque sorte une réponse à l'inquiétude exprimée par Réjean Savard qui s'interrogeait sur les rapports ténus entre les bibliothécaires, la bibliothèque et la lecture (Savard, 1998). Savard se demandait notamment comment et pourquoi une activité sociale et culturelle aussi importante, jadis au cœur de notre profession, en est venue à disparaître presque entièrement du discours des bibliothécaires à la fin du $\mathrm{XX}^{\mathrm{e}}$ siècle ; il en donne pour preuve la rareté des textes portant sur cette thématique dans Argus et Documentation et bibliothèques, le peu d'ateliers sur le sujet dans les congrès, le peu d'activités d'éducation permanente et de cours portant sur la lecture dans les programmes de formation des bibliothécaires. La cause en est-elle un affaiblissement du rôle social et culturel des bibliothèques et une "dérive techniciste" due à l'omniprésence des technologies de l'information? Savard se demandait, non sans raison, si les bibliothécaires n'étaient pas en train de laisser le problème de la lecture aux littéraires et aux spécialistes de la littérature de jeunesse.

En regard du questionnement sur les diverses facettes de la lecture, on ne peut écarter la question de l'alphabétisation et du rôle de la bibliothèque publique dans ce domaine (Fournier et Gagnon, 2000). Au tournant du siècle dernier, on évaluait à $28 \%$ le pourcentage de la population québécoise analphabète et à environ $54 \%$ la proportion des Québécois ne lisant pas au niveau nécessaire à un bon fonctionnement en société. La bibliothèque publique se doit d'apporter un soutien aux groupes d'alphabétisation, de mettre elle-même sur pied un programme d'alphabétisation. À l'écoute et au service de la clientèle particulière que constituent les adultes qui ont des difficultés en lecture, elle doit considérer comme une priorité la formation à la maîtrise de l'information et à l'utilisation de celle-ci. La bibliothèque publique a souvent négligé les adolescents, une clientèle à attirer et à séduire (Moreau, 2009). L'approche des adolescents à la bibliothèque doit être adaptée à ce groupe d'âge. Il est important de comprendre les comportements des adolescents en tant que lecteurs. Il faut les intégrer dans un projet, les impliquer, les inclure pour qu'ils se sentent concernés. Les adolescents doivent prendre la parole.

\section{Défense et illustration de la bibliothèque culturelle}

Deux personnes ont contribué d'une manière particulière à promouvoir l'aspect culturel de la bibliothèque publique au Québec. D’une part, Lise Bissonnette, l'ex-présidente-directrice générale de Bibliothèque et Archives nationales du Québec (BAnQ) et artisane de la genèse et de la construction physique et intellectuelle de la Grande Bibliothèque, et, d'autre part, le regretté Jean-Paul Baillargeon, statisticien et chercheur à l'Institut québécois de la recherche sur la culture, puis à la Chaire Fernand-Dumont de l'Institut national de la recherche scientifique. Bissonnette et Baillargeon n'ont pas inventé l'aspect culturel de la bibliothèque publique qui a toujours été présent dans la mission de ce type de bibliothèque, mais ils lui ont donné un relief particulier. Mettre la culture au premier plan dans la mission de la bibliothèque publique, c'est conférer au livre et à la lecture un rôle essentiel dans la société.

La création de la Grande Bibliothèque et les débats auxquels elle a donné lieu, de la décision de création jusqu'à son ouverture au public, puis le succès de la fréquentation dès l'ouverture, qui ne s'est jamais démenti par la suite, ont sans doute grandement profité à la bibliothèque, à sa mission, à son rôle, à son action, de même qu'à la diffusion de la culture et de la lecture dans la société québécoise tout entière. Depuis 2000, on a dit et on a écrit que la bibliothèque publique participait en première ligne au combat contre l'ignorance, 
qu'elle était un outil de démocratisation de la culture et du savoir. La bibliothèque publique est un lieu de proximité qui permet un dialogue entre tous les citoyens. Elle est surtout «la seule institution de transmission de la culture qui s'adresse simultanément à toutes les classes d'âge, à toutes les couches de la société, à tous les niveaux de scolarisation, à toutes les conditions de vie, elle est l'institution culturelle de proximité par excellence qui offre tous les vecteurs de culture " (Baillargeon, $2007: 31$ ).

Il faut admettre avec Lise Bissonnette que «les bibliothèques ont encore beaucoup à faire, elles-mêmes, pour s'insérer et s'affirmer sans complexe dans le territoire artistique et culturel (Bissonnette, 2004a : 363). Il importe de mettre en évidence le rôle culturel de la bibliothèque publique, étant bien entendu que la culture recouvre toutes les facettes de l'activité humaine, des aventures spirituelles et philosophiques jusqu'aux modes de vie. Dans son observation de la bibliothèque publique québécoise, Baillargeon a constaté que depuis le début des années 1990, celle-ci affiche un haut taux de fréquentation ou d'assistance par rapport aux autres pratiques culturelles et qu'elle est l'institution culturelle la plus intensément fréquentée par les usagers. Par ailleurs, il a aussi observé que la bibliothèque publique n'a pas au Québec une vision très claire de sa place et de son rôle dans l'ensemble des pratiques culturelles et dans la transmission de la culture (Baillargeon, 1998). Si la bibliothèque est le haut lieu par excellence de la transmission de la culture, le bibliothécaire se doit d'être un médiateur culturel. Même si les technologies de l'information ont transformé la pratique du métier de bibliothécaire au point d'en faire "l'un des plus «technologisés» au monde » (Bissonnette, 2004a : 363), il n'en reste pas moins que ce professionnel doit accorder à la lecture et à ses diverses facettes, la formation à l'utilisation de l'information, la contribution à l'alphabétisation, l'animation de la lecture, une importance considérable dans ses tâches professionnelles.

\section{Conclusion}

La bibliothèque est une institution sociale qui a subi, au cours des siècles, l'influence de beaucoup de facteurs à la suite notamment des trois révolutions du livre. Les pratiques de lecture ont bien changé avec le temps. On assiste aujourd'hui à une lecture plus fragmentaire, plus utilitaire où souvent le livre devient document (Pernin, 2008). L'ère du numérique interpelle la bibliothèque au cœur même de son fonctionnement. On a affirmé que le numérique transforme le rapport au savoir. Et qu'en est-il du lecteur? Le Loarer soutient qu' "avec le livre électronique, on voit et on lit une reproduction de livre imprimé et l'on perd le rapport physique à l'imprimé, à l'action de feuilleter pour lui substituer un écran à l'affichage de textes devenus volatils » (2002, 77-78).

\section{Il faudra constamment revenir à la charge pour promouvoir l'accès au livre et le goût de la lecture.}

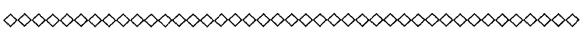

Depuis le développement d'une politique de lecture publique au début de la décennie 1970, on interroge les indicateurs de l'évolution des bibliothèques publiques, autonomes et régionales, créées dans les villes et les villages du Québec. Comment concilier développement des librairies, développement des bibliothèques et développement de la lecture? Le gouvernement a voulu poursuivre ces divers objectifs par le biais d'une politique du livre et le vote de plusieurs lois dans ce domaine. Une autre question récurrente des années 1980 à aujourd'hui : comment augmenter le taux d'abonnés à la bibliothèque publique, qui stagne autour de $30 \%$, en dépit d'un plus haut taux d'accessibilité et d'investissements considérables de l'État et des municipalités? Les deux grandes initiatives de la période, le plan Vaugeois au début de la décennie 1980 et la Politique du livre et de la lecture à la fin des années 1990, visaient à apporter une réponse forte à cette question de l'essor du livre et de la lecture chez la population du Québec.

La lecture publique est arrivée tardivement au Québec par rapport au reste du Canada et des ÉtatsUnis. Un demi-siècle, c'est peu pour implanter un solide réseau de bibliothèques et pour imposer de fortes habitudes de lecture. Le rôle de l'État s'est constamment avéré déterminant dans le développement du livre, de l'édition, de la lecture et de la bibliothèque chez nous. Il s'agit, selon les propos du premier ministre Lucien Bouchard lors du Sommet du livre et de la lecture, de «concilier affirmation de la spécificité culturelle et développement économique». Dans la foulée de la Politique du livre et de la lecture, la création de la Grande Bibliothèque et le succès obtenu depuis son ouverture en 2005, démontrent clairement que la poursuite de l'essor de la lecture publique n'est pas une vaine tâche. La population y a répondu avec enthousiasme.

Il n'empêche qu'au Québec, une bonne proportion de la population ne lit pas de livres, et cela pour des raisons diverses, dont notamment le manque d'intérêt, l'analphabétisme, l'absence de familiarisation avec l'écrit. Plusieurs études, enquêtes, coups de sonde ont fourni un portrait de cette réalité au cours des quatre dernières décennies. Il faudra constamment revenir à la charge pour promouvoir l'accès au livre et le goût de la lecture. Cet effort prendra une coloration différente dans l'avenir en raison de la concurrence des médias et surtout des moyens issus des nouvelles technologies de l'information et de la communication. Les modes de 
lecture subiront sans doute des modifications. Il appartiendra quand même aux bibliothèques et à ceux qui y œuvrent de rester au cœur de ce combat : les bibliothèques scolaires pour l'initiation au livre chez l'enfant et la bibliothèque publique pour la pratique de la lecture chez toute la population. $\odot$

\section{Sources consultées}

Alain, Jean-Marc. 1972. Recherches psychosociologiques sur les habitudes de lecture au Canada. Bulletin de l'ACBLF 18 (3): 191-197.

Baillargeon, Jean-Paul. 1998. Les bibliothèques publiques : nouveaux lieux privilégiés de développement culturel. Documentation et bibliothèques 44 (1) : 30-40.

Baillargeon, Jean-Paul. 2007. Plaidoyer pour une bibliothèque publique culturelle. Dix défis à relever. Montréal : ASTED.

Bissonnette, Lise. 2004a. La Grande Bibliothèque, portrait d'une institution. L'annuaire du Québec 2005. Montréal : Fides : 356-364.

Bissonnette, Lise. 2004b. Le rôle essentiel de la bibliothèque publique : la transmission de la culture ». In Jean-Paul Baillargeon (dir.), Bibliothèques publiques et transmission de la culture à l'orée du XXIe siècle. Québec; Montréal : IQRC; ASTED : 209-217.

Boisvert, Denis. 1994. En 2011, $46 \%$ de la population fréquentera la bibliothèque. Défi 9 (1-2) (novembre) : 46 .

Brault, Jean-Rémi (dir.). 1992. Les bibliothèques, une question de culture. Mémoires présentés à la Commission de la culture (1991). Montréal : ASTED.

Brunet, Lise. 1980. Les tendances de la recherche sur les habitudes de lecture au Québec. Documentation et bibliothèques 26 (4): 161-167.

Chartier, Anne-Marie et Jean Hébrard. 1989. Discours sur la lecture (1880-1980). Paris : Centre Georges-Pompidou, Bibliothèque publique d'information.

Comité d'étude sur les bibliothèques scolaires. 1989. Les bibliothèques scolaires québécoises, plus que jamais. Québec: Ministère de l'Éducation.

Commission d'étude sur les bibliothèques publiques du Québec. 1987. Les bibliothèques publiques, une responsabilité à partager. Québec: La Commission.

Delisle, Cynthia et Réjean Savard. 1998. L'École de bibliothécaires (1937-1962) : discours et formation. Documentation et bibliothèques 44 (4) (octobre-décembre) : 151-165.

Documentation et bibliothèques.1995. Numéro thématique sur la lecture publique au Québec, 41 (3) (juillet-septembre : articles de Gilles Gallichan (Les débuts de la lecture publique au Québec : 137-141), de Louis-Georges Harvey (période 1850 à 1900 : 143-146), de Marcel Lajeunesse (période de 1900 à 1960 : 147-151), de Jacques Panneton (période de 1960 à 1995 : 153-158).

Gagnon, Gilbert et al. 1997. La culture en pantoufles et souliers vernis. Québec : Publications du Québec.

Ferland, Benoit. 1998. Discours sur la lecture publique au Québec pendant la Révolution tranquille. Documentation et bibliothèques 44 (4) (octobre-décembre) : 185-198.

Fournier, Marie-Hélène et Stéphanie Gagnon. 2000. Alphabétisation et bibliothèques publiques : trois niveaux d'intervention possibles. Documentation et bibliothèques 46 (2) (avril-juin) : 85-93.

Gagnon, Gilbert. 1970. Habitudes et comportements des lecteurs, région de la Mauricie. Québec: Ministère des Affaires culturelles.

Gagnon, Gilbert. 1987. La politique des bibliothèques publiques et de la lecture au Québec (1960-1985). In Maurice Lemire (dir.), Le poids des politiques : livres, lecture et littérature. Québec : IQRC : 23-41.
Garon, Rosaire. 1984. Lecture et lecteurs au Québec. Documentation et bibliothèques $30(4): 111-120$.

Garon, Rosaire. 2004. 20 ans de lecture de livres au Québec. In Observatoire de la culture et des communications, Etat des lieux du livre et des bibliothèques. Québec: Institut de la statistique du Québec : 247-267.

Goyette, Marie (dir.). 2002. Politique culturelle et bibliothèque publique, lieu de diffusion des savoirs. Montréal : ASTED.

Harvey, Louis-Georges et Mark V. Olsen. 1986. La circulation de la bibliothèque de l'Institut canadien de Montréal, 1865-1875. Histoire sociale/Social History 19 (37) : 139-160.

Hébert, Pierre. 1997. Censure et littérature au Québec. Le livre crucifié 1625-1919. Montréal : Fides.

Hébert, Pierre. 2004. Censure et littérature au Québec. Des vieux couvents au plaisir de vivre 1920-1959. Montréal : Fides.

Lacroix, Yvon-André. 1979. Présent et futur des bibliothèques publiques du Québec. Documentation et bibliothèques 25 (4): 177-188.

Lafortune, Nathalie et Vincent Viens. 1998. L'évolution du discours des bibliothécaires sur la lecture publique dans le Bulletin de l'ACBLF entre 1955 et 1972. Documentation et bibliothèques 44 (4): 167-174.

Lajeunesse, Marcel. 1982. Les Sulpiciens et la vie culturelle à Montréal au XIX $X^{e}$ siècle. Montréal : Fides.

Lajeunesse, Marcel. 2005. Le bibliothécaire québécois : d'un homme de lettres à un professionnel de l'information. Documentation et bibliothèques 51 (2) : 139-148.

Lamonde, Yvan 1991. La bibliothèque de l'Institut canadien de Montréal (1852-1976) : pour une analyse mutidimensionnelle. In Territoires de la culture québécoise. Québec: Presses de l'Université Laval : 117-147.

Lamonde, Yvan et Patricia Fleming (dirs). 2004-2007. Histoire $d u$ livre et de l'imprimé au Canada. Montréal : Presses de l'Université de Montréal.

La lecture au Québec, document d'orientation. 1984. Québec: Ministère des Affaires culturelles.

Leroux, Éric et Marcel Lajeunesse. 2007. Le gouvernement du Québec et sa Politique du livre et de la lecture de 1998 : les objectifs et les réalisations. Documentation et bibliothèques $53(1): 27-41$.

Le Loarer, Pierre. 2002. L'édition électronique : rôle des médiateurs et nouveaux rapports au savoir. Documentation et bibliothèques 48 (3) : 71-80.

Moreau, Brigitte. 2009. Adolescence, lecture et bibliothèques publiques. Documentation et bibliothèques 55 (1) : 19-27.

Pernin, Frédérique. 2008. Petite philosophie du lecteur. Paris : Milan.

Savard, Réjean. 1997. Le discours sur la lecture et l'évolution de la bibliothèque publique au Québec de 1850 à 1950. Argus 26 (2) : 19-27.

Savard, Réjean. 1998. Le bibliothécaire, la bibliothèque et la lecture : triangle amoureux ou équation nulle. Documentation et bibliothèques 44 (4): 149 .

Savard, Réjean et Cynthia Delisle. 1996. Discours sur la lecture et les bibliothèques enfantines au Québec, 1930-1960. Cahiers de la recherche en éducation 3 (3) : 411-436.

Séguin, François. 1992. Bibliothèques publiques et faible lectorat. Documentation et bibliothèques 38 (3): 149-154.

Szpakowska, Janina-Klara. 1970. Profils culturels des jeunes Montréalais : livres, lectures et loisirs. Une enquête sociologique auprès des filles et des garçons de quinze, seize et dix-sept ans de la région de Montréal. 